with a full knowledge that they are of limited value, may be tried.

Another method for wounds of this nature is the alternative application of hypertonic and normal saline, according to the technique recommended by Sir Almroth Wright.

Granulating wounds are best treated by washing out with normal saline, or saline and eusol (see text). There is no need to wash out an ordinary abscess cavity.

Antiseptics can be applied to skin for sterilization purposes, but it is probably never wise to apply them to mucous surfaces except in very dilute solutions to wash the surface.

There is no doubt antiseptics have often been used perfunctorily and irrationally, and a great deal too much has been expected of and claimed for them. As Parry Morgan, a very judicial observer, states :-

"Antiseptics cannot do as much as is claimed for them. They certainly cannot sterilize the tissues subjacent to the surface of a wound, and, indeed, cannot be depended upon to sterilize an accessible surface, although they kill many of the organisms on it. . . . If we expect more from the antiseptics at present available we shall be disappointed."

The importance of realizing this, as Fleming wisely points out, is that if the surgeon once realizes that an antiseptic is but an accessory in the technique of wound treatment, he will be much more careful in the other parts of the treatment, i.e., the excision of damaged tissues, the provision of adequate drainage, and the careful dressing so that no other organisms get into the wound. Fleming, from an examination of wounds observed at a base hospital during the war, came to the conclusion that faulty technique in dressing the wounds was responsible for the almost universal presence of the streptococcus-the most dangerous of all the microbes found in wounds. $\mathrm{He}$ therefore pleads for a more lavish use of chemical antiseptics outside the wound. All the things which come near a wound should be sterilized by heat or antiseptics, and in the case of every raw surface a dressing should be applied which should not only be itself sterile and cover considerably more than the area of the wound, but it should also contain some substance which should at least inhibit the growth of organisms in the serous discharges which soak the dressings, and kill any stray organisms which contaminate the outer part of the dressing. But it must be remembered that the presence of an antiseptic in the dressing should not in any degree cause the surgeon to abate his meticulous care in dealing with the wound.

\section{MEDICINE AND THE STATE.}

SUMMARY OF A LECTURE DELIVERED

$$
\begin{gathered}
B y \text { DAVID C. KIRKHOPE, } \\
\text { M.D., cH.M., D.P.H., }
\end{gathered}
$$

Medical Officer of Health; Medical Officer, Tottenham Maternity and Child Welfare Committee.

AT THE PRINCE OF WALES hospital, TOtTENham, ON JUNE 28, 1927.

IT would be impossible in the time at my disposal to give anything like a complete account of the relations of the State with Medicine. Yet it appears to be necessary, or at least desirable, that at one time or another I should treat of the subject, at any rate, broadly. The Ministry of Health was formed to consolidate all the health services in their central administration within itself. This has not yet been accomplished. For the Board of Education -in respect of children of school age-the Home Office in respect of prisons and factories (and? lunatic asylums), and the Ministry of War in respect of the Army and Navy, have their own special medical departments. I do not purpose to deal with all of these, and in respect of the Ministry of Health and Board of Education only in so far as their oversight concerns the adminis- 
tration of the local health services of a municipal authority. There will thus be excluded from our consideration, Poor Law Administration and the National Health Insurance Scheme.

The accounts of every local authority are subject to Government audit, and improperly incurred expenditure is subject to surcharge, the councillors assenting thereto being made financially responsible. All health services are sanctioned by statute, and it is imperative that inquiry shall be made before any moneys are expended whether such expenditure can legitimately be made.

Thus by Section 4 of the Infectious Diseases (Notification) Act, I889, the local authority shall gratuitously supply forms of certificates to local practitioners, and shall pay 2 s. $6 \mathrm{~d}$. for each such certificate sent by a medical practitioner in private practice, and Is., if from the medical officer of a public body or institution. There is a liability to a fine not exceeding 4os. for failure on the part of the practitioner to comply with the Act.

Contrast this with the Notification of Births Act, 1907, where the same obligation is imposed, amongst others, upon the medical practitioner in attendance at the birth. There is liability to a penalty of 20 . for failure to notify, but a local authority has no power to pay for the notification.

The Infectious Disease (Notification) Act defines the notifiable diseases, viz., small-pox, cholera, diphtheria, membranous croup, erysipelas, scarlatina, or scarlet fever, typhus, typhoid, relapsing, continued and puerperal fever and any other to which this Act has been made to apply by a local authority, with the approval of the Ministry of Health.

The Local Government Board, as it then was (the Ministry of. Health, now), reserved to itself powers to make, alter and revoke regulations, with a view to the treatment of persons affected with cholera, or any other epidemic, endemic or infectious diseases and preventing their spread (P. H. Act, I875, s. I3o).

Regulations have thus been made requiring the notification of acute primary pneumoni acute influenzal pneumonia, tuberculosis:ophthalmia neonatorum, cerebro-spinal feves acute poliomyelitis, acute polio-encephaliti흘 and encephalitis lethargica.

Following Notification-Treatment?

By Section I3I, P. H. Act, I875-anழ local authority may provide for the use of the inhabitants of their districts, hospitals $\overrightarrow{\mathrm{tb}}$ temporary places for the reception of the sicis but compulsory removal thereto of an person suffering from any dangerous infecio tious disease who cannot be properly isolate can only be effected by the order of a justicte unless the person is lodged in a commol lodging-house (Sec. 124, P. H. Act, 1875, and Sec. 65, P. H. Acts Amendment Act, 1907)

The local authority may also provide nurses for attendance upon patients suffering from infectious diseases, who, owing to want of hospital accommodation, or wles the removal is liable to endanger heafing cannot be removed to hospital (Sec. P. H. Act, 1907). But this section does not diminish or remove the obligation to provide proper hospital accommodation for persor: suffering from infectious disease.

A local authority has power (Sec. I3 P. H. Act, 1875) to recover from a patie if the cost of his treatment in an infectious diseases hospital. The authority is permis. sive, not obligatory.

Further, the claim can only be made against the patient, not the parent of guardian, or employer, unless under coutract. Further, by Section 6o, P. H. AGt 1907, "Nothing in Section I32, P. H. A 1875, shall require the local authority to recover the cost, where the local authority have satisfied themselves that the circum. stances of the case are such as to justify the remission of the debt."

The remission of the debt is usualfy justified on the grounds that the patient was removed as a measure of public safety, ang not merely for the treatment of the individuat 1 patient, and where recovery of debts of this 
kind has been attempted, the expenditure upon collection has frequently exceeded the amount received.

The following diseases, if contracted in a factory or workshop, are notifiable to the Chief Inspector of Factories, Home Office, penalty for omission, 40s. namely, poisoning by lead, phosphorus, arsenic, mercury, carbon bisulphide, aniline and benzene, anthrax, toxic jaundice, epitheliomatous ulceration and chronic ulceration.

Tuberculosis of any organ is notifiable to the Medical Officer of Health of the district in which the patient resides. There are three forms of notification : (A) being for medical practitioners; (B) for school medical officers, and (C) for medical officers of poor law institutions or sanatoriums. The duties of the Medical Officer of Health receiving the notification are threefold: (I) Keep a register; (2) make a weekly return of notifications to the County Council ; (3) take steps for investigating the source of infection for preventing spread, and removing conditions favourable to infection. That is to say, the duties of the Local Medical Officer of Health relate to environmental conditions. Upon the County Council or County Borough Council devolves the treatment of the patient. This is effected by means of local dispensaries, sanatoriums, hospitals (including poor law institutions).

You are probably better acquainted than I am with the measures employed in the treatment of tuberculosis, but from the point of prevention, it is worthy of note in passing that now, at length (Prevention of Tuberculosis Regulations, 1925), power is given to local authorities to prevent tuberculous persons handling milk or milk vessels in the course of production or distribution.

A local authority may provide and maintain a carriage or carriages for removal of infectious cases (Sec. I23, P. H. Act, I875).

The Venereal Diseases Act, 1917, prohibits unqualified practice in the treatment of venereal diseases, and empowers the Ministry of Health to approve schemes by counties and county boroughs for the gratuitous treatment of venereal diseases, i.e., syphilis, gonorrhiea, or soft chancre.

Any local authority may, with the sanction of the Ministry of Health, themselves provide, or contract with any person to provide a temporary supply of medicine and medical assistance for the poorer inhabitants of their districts (Sec. I33, P.H. Act, I875). This section is taken advantage of to provide such remedies as anti-diphtheria serum, antiscarlet fever serum, anti-streptococcus serum, anti-tetanus serum, insulin, \&c.

I have been dealing with infectious diseases up to this point. A local authority has no inherent power to treat general diseases. The nearest approach to that has been a permission to make reasonable subscriptions or donations to voluntary hospitals not to exceed in any one year the product of a penny rate (Sec. 64, P. H. Act, 1925). Power is also given to provide ambulances for the conveyance of sufferers from other than infectious diseases (Sec. 63, P. H. Act, I925).

The Education (Administration Provisions) Act, 1907, imposed a new order of things upon local education authorities, namely, the medical inspection of children of school age. This Act has now been incorporated in the Consolidating Act of I92 I; and it may suffice if I state its provisions shortly :-

Section 80 requires local education authorities for elementary education to make such adequate and suitable arrangements as may be sanctioned by the Ministry of Health, for attending to the health and physical condition of children educated in public elementary schools.

A duty is imposed upon higher education authorities also to provide medical inspection for their scholars and gives them the power to make arrangements for attending to the health and physical condition of such children and young persons. Neither education authority may establish a general domiciliary service of treatment by medical 
practitioners. The local education authorities are required to recover from parents an amount not exceeding the cost of treatment, unless the parents are unable to pay. This last provision is by no means vigorously enforced, and it is admitted that much treatment is given free of charge.

Under this section clinics have been established for the treatment of children's ailments, including minor ailments, ringworm, tonsils and adenoids, otorrhœa by ionization, dentistry, including orthodontics, convalescent treatment, orthopædics.

This Education Act of I92 I places on local education authorities the obligation of making special provision for defective children, crippled children, blind, deaf and dumb, and epileptic children.

The amount of incapacity occurring amongst children of school age, amounting to about $\mathrm{I}, 000,000$ at any moment, directed the attention of the Ministry of Health to the pre-school period of childhood, and as a consequence the Maternity and Child Welfare Act was passed in I9I8.

Prior to that, however, the Notification of Births Acts of 1907 and 19I5-already noted-had paved the way for the ascertainment of the number and place of births in each local government area.

A circular (M. and E.W. 4) issued by the Ministry of Health, gives some indication of the scope of the provisions allowed :-

(a) Home visitation (which has already been permitted under the Notification of Births Act. (b) Establishment of clinics or centre्टs for expectant mothers, and childre under 5 years of age.

(c) Home helps in confinement caseg.

(d) Home nursing for expectant an nursing mothers, and children under $\widetilde{\mathbb{q}}$ years of age, for measles, whooping cough, poliomyelitis, epidemic did rrhou, ophthalmia neonatorum.

(e) Hospital treatment for childreg under 5 years of age.

$(f)$ Lying-in homes.

(g) Payment of midwives' fees.

(h) Day nurseries.

(i) Convalescent home treatment.

(j) Experimental work in connectio with children under 5 years of age, and expectant and nursing mothers.

(k) Provision of food and milk.

The regulations respecting puerpera pyrexia and puerperal fever have given lored authorities power to provide for $(a)$ seconep opinion, (b) pathological examination ôे of blood and lochia, (c) nursing assistance, institutional treatment, at the public cost, for such patients as are judged by the practitione in charge of the case to require any of those services.

A local authority may equip a bacterio logical and pathological laboratory for the furtherance of preventive medicine.

It is for the general practitioner to kno

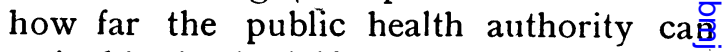
assist him in the fulfilment of his duties ang to call upon them for aid whenever and wherever that aid can be serviceable to hing

THE following Special Lectures will be given at the West London Hospital Post-Graduate Collegay Hammersmith, W., at 4.30 p.m., unless otherwise stated. These lectures are free.

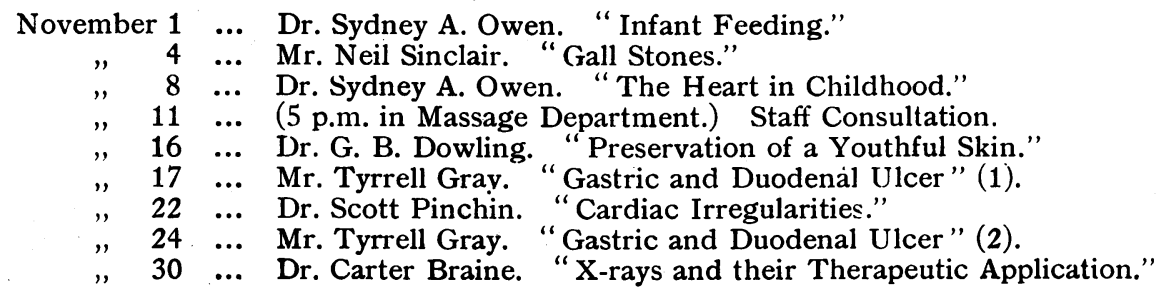

